\title{
Malaysia Private Entity Reporting Standard (MPERS) adoption for SMEs: Insights from Accounting Practitioners in Malaysia
}

Nurul Nazlia Jamil (Corresponding author)

Faculty of Economics and Muamalat, Universiti Sains Islam Malaysia (USIM), Malaysia E-mail: nurulnazlia@usim.edu.my

Nathasa Mazna Ramli

Faculty of Economics and Muamalat, Universiti Sains Islam Malaysia (USIM), Malaysia E-mail: nathasa@usim.edu.my

Ainulashikin Marzuki

Faculty of Economics and Muamalat, Universiti Sains Islam Malaysia (USIM), Malaysia E-mail: ainulashikin@usim.edu.my

\author{
Nurul Nadiah Ahmad \\ College of Business, Management and Accounting \\ Universiti Tenaga Nasional (UNITEN), Malaysia \\ E-mail: Nadiahn@uniten.edu.my
}

Received: February 20, 2020

Accepted: April 7, $2020 \quad$ Published: April 15, 2020

doi:10.5296/ber.v10i2.16847

URL: https://doi.org/10.5296/ber.v10i2.16847

\begin{abstract}
Small and medium enterprises (SMEs) have very significant contribution to economic growth of the countries as more than $95 \%$ of companies worldwide and employment are represented by the SMEs industries. Therefore, in increasing the harmonization of reporting standard of SMEs, Malaysia is moving aggressively towards the efforts by introducing the Malaysian
\end{abstract}


Private Entity Reporting Standard (MPERS) for SMEs starting from $1^{\text {st }}$ January 2016 onwards. MPERS is seen to bring opportunities to the business as it is adoption of international standard that has been designed to fits the local needs and the customization to the Malaysian business environment could ensure comparability of the locals with the international business. Hence, this research attempt to 1) examine the perceptions of accounting practitioners on MPERS implementation and 2) identify the problems encountered in applying MPERS in SMEs. This study provides pioneering evidence on the problems of the practitioners encountered when applying the MPERS through the 176 questionnaires survey that have been distributed to the accounting practitioners that involve with MPERS implementation for SMEs in Malaysia. The insights and perceptions obtained highlighting new dimensions to the inherent problem such as issues of consistency and guidance in applying the MPERS with the cost-effective manner. Thus, the issues of differences in judgements among the practitioners become a phenomenon in relation to the application of MPERS for SMEs. The findings of this study are of interest to standard setters and SMEs stakeholders in Malaysia and other countries.

Keywords: Accounting, Small Medium Enterprises (SMEs), Financial Reporting, Malaysia

\section{Introduction}

Small and Medium Enterprises (SMEs) has becoming as part of majority in the business entities. Therefore, the role of SMEs in the economic development cannot be overemphasized as SMEs make significant contributions to the global trade and economic growth (Pais and Bonito, 2018; Chen, 2006). In ensuring that SMEs can scale up their operations specially to fulfilling their financial needs, hence maintaining proper accounts and generating meaningful financial statements are giving huge impact to their business. In addition, SMEs are encouraged to attract foreign investment, in which SMEs reporting also needs to meet the international requirement and standards that has been set by the International Accounting Standard Board (IASB). However, in response to this fast-growing economy and globalization, the international accounting standard (IASs) are becoming too complicated, costly and demotivating the SMEs to apply in an effective manner.

The introduction of the new MPERS by the Malaysian Accounting Standard Board (MASB) in 2014 set a new milestone for financial reporting of private entities in Malaysia. Effective for financial statements with annual periods beginning on or after Jan 1, 2016 the private entities will no longer adopt the Private Entities Reporting Standard (PERS). The misconception is that by default the adoption of MPERS is the only choice for private entities. In fact, a private entity has the option to either adopt MPERS or Malaysia Financial Reporting Standard (MFRS) in its entirety. Previously, SME companies refer to the Private Entity Reporting Standard (PERS) which is considered outdated as it was based on the previous IAS effective 2003 (Aziz et al., 2019). Due to this matter, the management needs to identify the gap and analyses the implications to ensure a smooth transition into the new reporting framework.

On the other hand, SME financial reporting has been a controversial issue. There are many debates since decades about accounting standard for SMEs (Harvey \& Walton, 1996; Holmes 
et al., 1991 and Walton, 1992). Besides, as a part of policy to reduce regulatory burdens for business entities, financial reporting regulations have been identified as a burdensome requirement imposed on SMEs. Apart from the issue of cost reduction, there exists an argument about the needs of SME financial statement users. Therefore, the extent of concessions and relaxations from the financial reporting obligations granted to SMEs varies between jurisdictions.

In Malaysia, MPERS seen as one of enhanced reporting for SMEs as it can improve the consistency and comparability of the local SME companies. This is due the fact that MPERS is based on the IFRS for SMEs as proposed by the IASB. The standard has been adopted by almost 73 countries including United Kingdom, Singapore, Australia and many others. MPERS has been shaped following to the local needs and environment at the same time comply with the global standard. For Malaysia, SMEs mainly measure by the performance of gross domestic product (GDP). For year 2018, Malaysia's SMEs GDP grew at 6.2 per cent as compared to 7.1 per cent in 2017. Given the important role of SMEs in economic development, the survival and growth of SMEs is vital to the overall health of the economy. The Malaysia government has implemented a broad range of policies and programme to enable them to grow, innovate and compete.

The need of efficient financial reporting to ensure the sustainability of SME's business, hence MPERS is introduced with the objective to establish guidance and to ease the reporting burden for an entity's first financial statements prepared in accordance with the MPERS. This recent change in SME financial reporting in Malaysia implies that, as with MPERS, the objective of financial reporting is geared toward decision usefulness and its focus is on the needs of private entities. Indeed, this paper attempts to answer the following objectives: 1) examine the perceptions of accounting practitioners on MPERS implementation and 2) identify the problems encountered in applying MPERS in SMEs.

\subsection{Problem Statement}

SMEs financial reporting regulatory framework is complex, especially SME are representing the majority portion in the GDP on Malaysia. The opportunity to reduce the burden in reporting could highlight a benefit to the important sector for Malaysia's economy. Therefore, the implementation of MPERS is one potential route towards simplifications that is worth evaluating. Due to the infancy of studies in MPERS implementation, this research draws on studies by Rahman and Hamdan (2019), Aziz et al. (2019) and Jamil et al. (2020) to extend on previous research available in Malaysia context and address the issues on the perceptions of accounting practitioners in implementing the MPERS.

Furthermore, in the debate on SME financial reporting that presently occurring in many countries, the exploration study on MPERS can be the benchmark of financial reporting across ASEAN regions due to the similar business setting and environments. It is expected that the empirical findings on this study will be of interest to national regulators and accounting standard setters in Malaysia and other countries specially to consider the simplification financial reporting requirements for SMEs. 


\section{Macrothink}

The formulation of financial reporting policy that can meet the reporting needs of SMEs in Malaysia would give greater advantage in the SME sector as a whole and therefore, it is becoming significant to consider the cost and benefits of MPERS implementation. In addition, as mentioned by Pais and Bonito (2018), countries like Malaysia that permit or require the use of IFRS for listed companies and have a common legal system, can reduce the costs of developing their own financial accounting standard as with familiarity of the IFRS environment it implies a reduction in transaction costs as well. This is consistent with study by Isidro et al. (2016) highlighted that other than institutional factor, adding more factors add little incremental explanatory power on the adoption of IFRS on SMEs. The additional factors could be; educational level, common law legal system and national accounting standard.

Another justification for MPERS lies in the consideration of the user's need and secondly the cost and benefit constraint. According to Rahman and Hamdan (2019), the objective of general purpose financial statement is to provide information about the financial position, performance and the changes in financial position of an entity that is useful to a wide range of users in making economic decision. Thus, the exploration study on MPERS implementation are needed in acknowledging that the types and needs of users of SME's financial statements maybe different to those of user of financial statements of larger entities.

The debate on the introduction of MPERS also due to no new PERS standard issued by the MASB although there have been significant changes, developments and improvements to the MFRS in the last 11 years, and the PERS standard have not been updated to incorporate these changes. There is thus an 11 years gap between PERS and the latest reporting framework.

This study is organized as follows, where Section 2 reviews the literature that has been published in the area. Section 3 describes the research methods used for data collection and section 4 report the results. Finally, the Section 5 draws conclusions, states the implications and suggestions for future research. It also covers the limitations faced by the researcher.

\section{Literature Review}

This paper intends to extend the current literature on MPERS in Malaysia as during the present time, there are lacking empirical evidence on the MPERS implementation. MPERS shall be effective for annual periods beginning or after 1 January 2016, but early application is permitted. The most significant change is that private entities are allowed the option of revaluing property, plant and equipment. Private entities that are applying the revaluation model under the existing PERS will certainly welcome this amendment because they can continue applying the revaluation policy when they adopt the MPERS. The other amendments mainly clarify existing requirements or add supporting guidance, rather than change the underlying requirements in the MPERS. Private entities that wish to apply the amendments early, instead of for annual periods beginning on or after 1 January 2016, must apply the amendments in their entirety. 


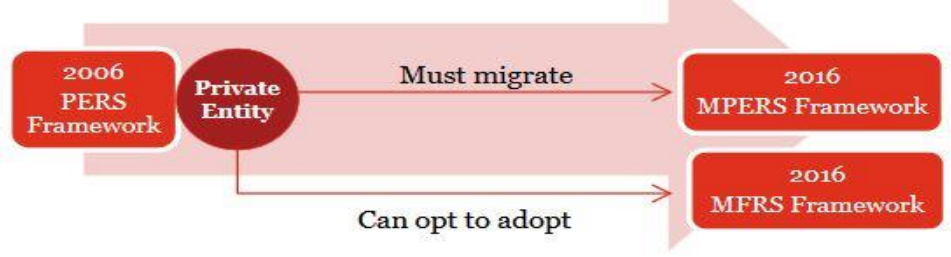

MPERS defines a private entity as a private company incorporated under the Companies Act 1965 that is not a company required by the Securities Commision or Bank Negara to prepare or lodge any financial statements. In addition, a private entity is not a subisidiary or associate of or jointly controlled by, an entity that is required by the Securities Commission or Bank Negara to prepare lodge any financial statements. There are main differences between MPERS and IFRS for SMEs as refer to Table 1 below:

Table 1. Difference between MPERS and IFRS for SMEs

\begin{tabular}{|l|l|l|}
\hline & MPERS & IFRS for SMEs \\
\hline Scope & Applicable to Private Entities & $\begin{array}{l}\text { Applicable to SMEs without public } \\
\text { accountability }\end{array}$ \\
\hline $\begin{array}{l}\text { Exemption from } \\
\text { consolidation }\end{array}$ & $\begin{array}{l}\text { Ultimate Malaysian parent is required to } \\
\text { prepare consolidated financial statements, } \\
\text { regardless of whether its ultimate parent (not } \\
\text { incorporated in Malaysia) prepares } \\
\text { consolidated financial statements. }\end{array}$ & $\begin{array}{l}\text { A presenting contity is exempted from } \\
\text { statements if it is a subsidiary and its } \\
\text { ultimate parent produces consolidated } \\
\text { financial statements that comply with full } \\
\text { IFRS or IFRS for SMEs. }\end{array}$ \\
\hline $\begin{array}{l}\text { Revenue from } \\
\text { property } \\
\text { development } \\
\text { activities }\end{array}$ & $\begin{array}{l}\text { Guidance is based on the Malaysian-specific } \\
\text { requirements in MASB 32 'Property } \\
\text { Development Activities'. }\end{array}$ & $\begin{array}{l}\text { Guidance is based on IFRIC } \\
\text { 'Agreements for the Construction of Real } \\
\text { Estates'. }\end{array}$ \\
\hline $\begin{array}{l}\text { Income tax } \\
\text { Accounting for income taxes are consistent } \\
\text { with the requirements of MFRS 112 'Income } \\
\text { Taxes' }\end{array}$ & $\begin{array}{l}\text { The requirements are based on the IASB's } \\
\text { 2009 Exposure Draft on income taxes. }\end{array}$ \\
\hline
\end{tabular}

When the IFRS for SMEs was issued in 2009, the IASB stated that it planned to undertake an initial comprehensive review of the standard after two years of use by SMEs. Specifically, the IASB said it would consider whether to amend the IFRS for SMEs to address any implementation issues identified and to consider any changes made to IFRS since the IFRS for SMEs was issued. On 21 May 2015 the IASB issued limited amendments to the IFRS for SMEs. Most of the amendments clarified existing requirements or add supporting guidance, instead of changing the underlying requirements in the IFRS for SMEs. The most significant changes, which relate to transactions commonly encountered by SMEs, are: 1) permitting SMEs to revalue property, plant and equipment and 2) aligning the main recognition and measurement requirements for income taxes with IFRS. 
According to Wichman (1983), accounting has become a major challenge for SMEs business entities and according to McMahon (1999) finds that financial reporting practice in SMEs appear to lose the standards recommended by the various external financial information users. In another study by Lalin and Sabit (2010) highlighted that the regulations as the main drivers why SMEs prepare the financial statement. While other study such as Olson et al. (2004), discovered that the number of users of accounting information in SMEs is increasing include the stakeholder in supply chain industries., Therefore, it is believed that the financial reporting play significant role in SMEs but argues that the report must be adjusted in order for them to be understood and cost efficient. The introduction of MPERS is timely given the increasing prominence of local private entities and SMEs in the regional and global markets. Simultaneously, this is seen as vital step in preparing local private companies for globalization as well as the challenges that come with it.

Previously in Malaysia, the SMEs reporting standard was PERS which was close to the old International Accounting Standard (IAS). However due to the various arguments such as the accounting activities in the SMEs are more concerned with legal compliance than economics relevance (Aziz et al., 2019; Jamil et al., 2020), therefore SMEs have been criticized for having poor financial reporting quality. As an overall the requirements and guidance in MPERS would generally be sufficient to SMEs private entities in Malaysia, however MPERS does not come with detailed application guidance in some complex areas. Large private entities may need to refer to the guidance in the MFRS framework for their accounting requirements. For instance, some large private entities with significant research and development activities (including IT and software development activities), entities that have capitalized borrowing costs previously and entities with significant amount of purchased goodwill, they may find adopting MPERS a disadvantage because the option of capitalizing development costs or borrowing costs has been removed and purchased good will must be subject to annual amortization. Hence, this research fulfilling the gap to explore the perceptions of accounting practitioners and identifying the challenges in implementing the standard.

\section{Research Methodology}

A survey was conducted on accounting practitioners in Malaysia to explore their perceptions on the MPERS implementation and identify the problems they encounter in applying the MPERS on SMEs in Malaysia. The survey was conducted in between July to October 2019. The accounting practitioners therefore already applying the standard when the survey was conducted, affected entities for annual periods beginning on or after 1 January 2016, must apply the amendments in their entirety. Therefore, they were well suited to provide evidence of the difficulties they faced when applying this new standard.

The respondents at all cases, had exposure to MPERS though their knowledge and experience varied. All participants were geographically located in Klang Valley and Selangor as the main commercial centers in Malaysia. A total of 176participants took part in the survey.

The research instrument comprised of two sections. The first section required subjects to provide demographic data such as gender, level of formal education, level of experience and 


\section{Al Macrothink}

Business and Economic Research ISSN 2162-4860 2020, Vol. 10, No. 2

firm details. The second section consisted of 28 statements, each of which addressed various aspect of MPERS for SMEs in Malaysia. The respondents were asked to indicate their level of agreement or disagreement with each of those statements on a five-point Likert scale. The statements were developed on the basis of criticism and comments on MPERS for SMEs by academic and professional literature.

\section{Results and Discussion}

\section{Validity of Research Instrument}

In order to ensure the internal validity and consistency of statements contained within the research instrument, Cronbach's alpha was calculated. According to Nunnally (1978) a Cronbach alpha of 0.7 or greater indicates satisfactory internal consistency. Since a Cronbach alpha of 0.962 was obtained, a very high level of internal consistency across the 28 statements.

Table 2. Reliability Statistic

\begin{tabular}{|l|l|}
\hline Cronbach Alpha & Number of Items \\
\hline 0.962 & 28 \\
\hline
\end{tabular}

Table 3. Demographics data of respondents

\begin{tabular}{|l|l|}
\hline Demographic data & Respondents \\
\hline Sample & 176 \\
\hline Age (Mean) & 30.5 \\
\hline Gender: & \\
\hline Male & $47.7 \%$ \\
\hline Female & $52.3 \%$ \\
\hline Years being Professional Accountant (Mean) & 6.7 \\
\hline Present Firm Category: & \\
\hline Big Four Accounting Firms & $46.3 \%$ \\
\hline Non- Big Four Accounting Firms & $53.7 \%$ \\
\hline Job Tenure with the Present Firm (Mean) & 4.7 years \\
\hline Field of Works: & \\
\hline Accounting & $39.5 \%$ \\
\hline Auditing & $40.1 \%$ \\
\hline Taxation & $20.4 \%$ \\
\hline
\end{tabular}

\section{Demographic details of respondents}

Table 3 highlighted summary of demographic information related to the 176 respondents. As shown in Table 3, the mean age of the respondents was 30.5 years. While about $47.7 \%$ of the respondents were male and $52.3 \%$ being female. In average, years of the respondents being 
professional account was 6.7 years. Of the 176 respondents, $46.3 \%$ of them were being employed by the Big Four accounting firm, while the other $53.7 \%$ being employed by non-Big Four accounting firm. On the other hand, the average job tenure of the respondents currently working with their present firm was 4.7 years. Since the respondents were varied in term of their fields, the results indicated that $39.5 \%$ of them were from accounting practitioners, $40.1 \%$ were doing auditing and around $20.4 \%$ were coming from taxation field.

\section{Problem posed by MPERS for SMEs}

In order to provide a more detailed analysis of the various issues surrounding the application of MPERS for SMEs, 28 statements were organized into those relating to the cost and benefits in applying the standards, lack of consistency across the MPERS for SMEs, the extent of vagueness and repetition in MPERS for SMEs, the extent of understandability, extent of guidance provided, and other issues in interpreting and applying MPERS for SMEs. A summary of the 28 statements and the descriptive is provided in Table 4 (Refer Appendix 1).

\section{Cost and Benefits}

About four questions (Questions 1, 7,9 and 21) were included in the survey to gather opinions from the practitioners on the cost of compliance with the MPERS. For the purpose of analysis, it is expected that the respondents would answer 4 and above using five-point Likert scale, 1 denoted 'strongly disagree' and 5 is 'strongly agree' for these statements would generally be indicating that they agreed with the relevant statements. Based on the result, it shows that $65.3 \%$ of respondents agree that the cost of complying with the MPERS are far greater than the corresponding benefits (Question 1). In addition, regards to the information required to apply MPERS is not available or available with only undue cost or effort (Question 7), the result indicates that $43.4 \%$ of respondents agree with the question. Furthermore, about $52.6 \%$ agreed that the use of FVA in MPERS imposes significant annual costs on preparers and is not justified on cost or benefit grounds (Question 9). While regards to the additional exemptions need to be given in MPERS to make it cost effective for SMEs in Malaysia (Question 21), about $57.1 \%$ of respondents agreed with the statements.

Thus, this result highlighted that for SMEs operating in Malaysia, the cost of compliance for SMEs became excessive especially for the small size of SMEs consistent with studies conducted by Buchanan (2003), Haller (2003) and Coppens et al. (2007). This is due to the reason that they have to hire outside expertise in order to comply with the standard (Coppens et al., 2007; Jamil et al., 2020). Some other studies mentioned that the adoption of standard hindered by the cost of compliance and complexities for small companies such as in United Kingdom (Fearnly and Hines, 2007), Canada (Maingot and Zeghal, 2006) and US (Herman, 2010).Similarly, recent study conducted in EU regards to the harmonization of reporting standard for SMEs by Hyblova (2019) highlighted that the costs of financial statement creation and staff training would increase as the result of standard implementation. Therefore, the small business would have very limited access to the corporate training. 


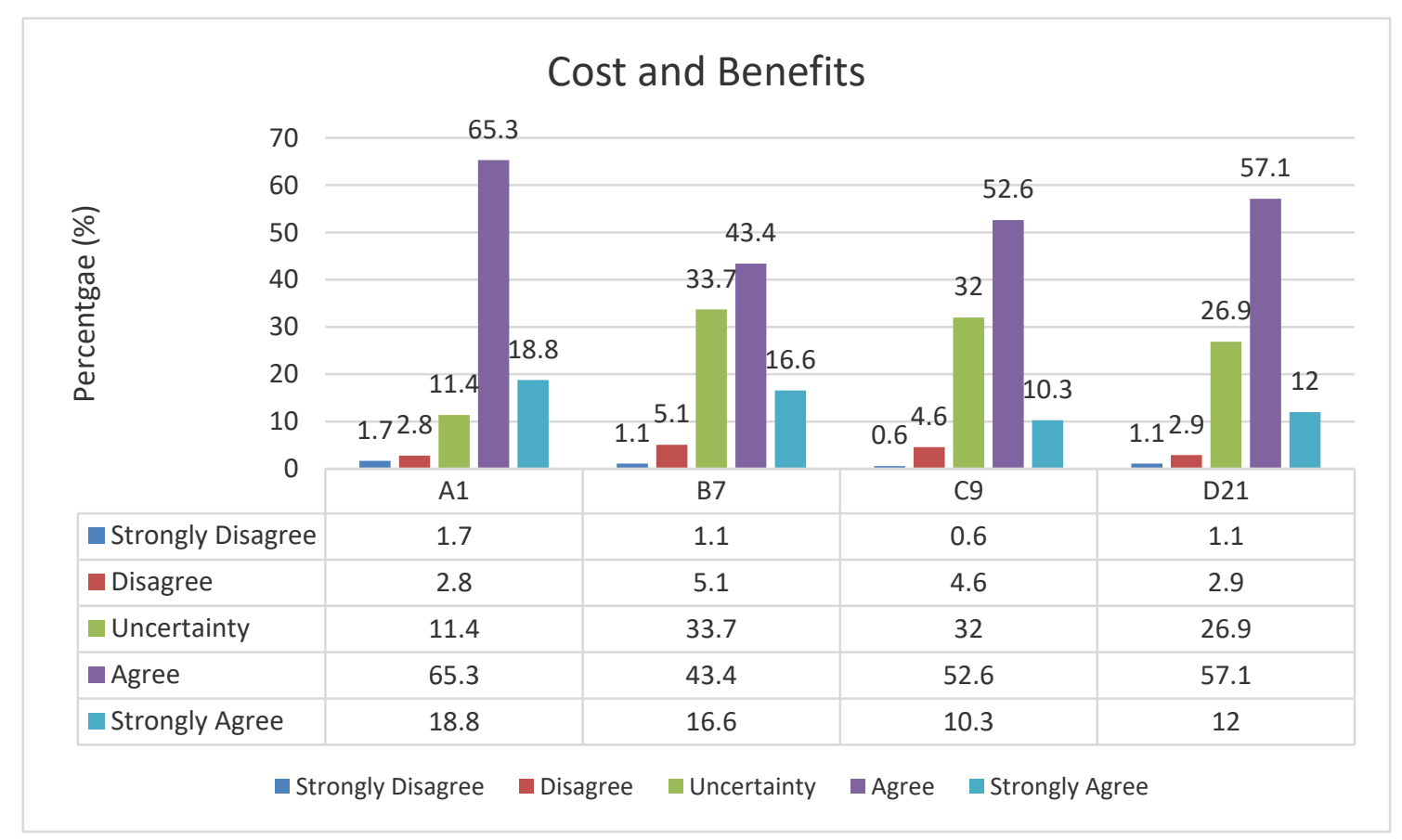

\section{Cost and Benefits}

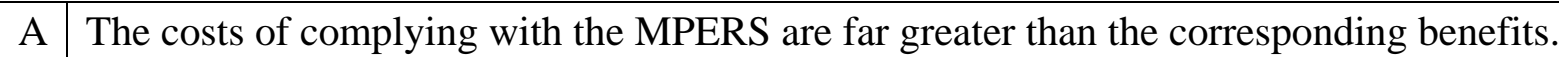

B The information required to apply MPERS is not available or available with only undue cost or effort.

C The use of FVA in MPERS imposes significant annual costs on preparers and is not justified on cost/benefit grounds.

D Additional exemptions need to be given in MPERS to make it cost effective for SMEs in Malaysia.

\section{Lack of consistency in MPERS for SMEs}

There were four questions (Question 14, 15, 23 and 25) highlighted in the survey related to the degree of consistency of MPERS throughout its implementation. For the purpose of the analysis, it is expected the respondents would answered 4 as to show their agreement towards to the questions which denoted by five likert scale. The result shows that $50.3 \%$ agree recognition criteria applied are not applied consistently across the MPERS (Question 14). However, in terms of measurement (Question 15), about $45.1 \%$ of respondents agree in term inconsistency related to the measurement applied in MPERS. On the other hand, regards to the term definition used in MPERS (Question 23), about 55.4\% agreed the definition used is not consistent. This is more or less the same with Question 25, 52\% of respondents agreed that the terms used in MPERS were inconsistence. Due to the inconsistence terminologies used, therefore lead to the wrong interpretation and cause problems when applying the MPERS through out the SMEs which have various industries. These findings in agreement with study conducted by Vanauken et al. (2017) which provide evidence that accurate financial information in the report needs to provide the foundation for decision making, while 


\section{Macrothink}

Business and Economic Research

ISSN 2162-4860

2020, Vol. 10, No. 2

at the same time it is to ensure the degree of consistency and reliability in predictions about the impacts towards to the performance of the companies.

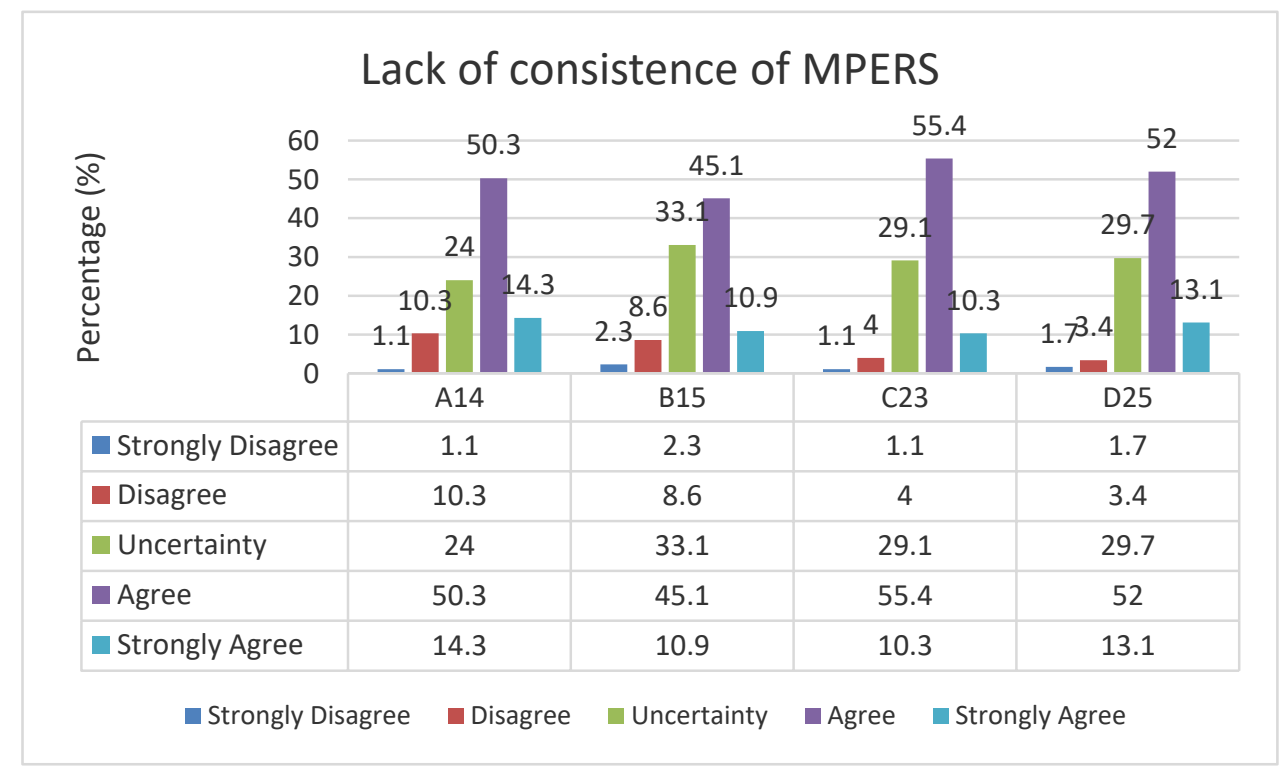

\begin{tabular}{|l|l|}
\hline \multicolumn{2}{|l|}{ Lack of consistency in MPERS } \\
\hline A & Recognition criteria applied are not applied consistently across the MPERS. \\
\hline B & Measurement criteria applied are not applied consistently across the MPERS. \\
\hline C & Certain terms are not defined in the same way across the MPERS. \\
\hline D & Some terms in MPERS are used inconsistently. \\
\hline
\end{tabular}

\section{Extent of vagueness and repetition in MPERS for SMEs}

In order to check the accountant view on the principle based understanding of the standard, the extent of vagueness and repetition in MPERS have been included in the Question 4 and Question 11. About $51.5 \%$ of the respondents, agreed that MPERS contain expressions that are lacking clarity and about $49.1 \%$ of the accounting practitioners found that the individual paragraph within the MPERS are repetitive. Therefore, due to this vagueness lead to the inherent problem in applying and interpreting MPERS in effective way as this is consistent with Zebda (1991) mentioned about vagueness has been argued to be a significant source of inexactness in many accounting decision problems and resulted to the data be less useful. 


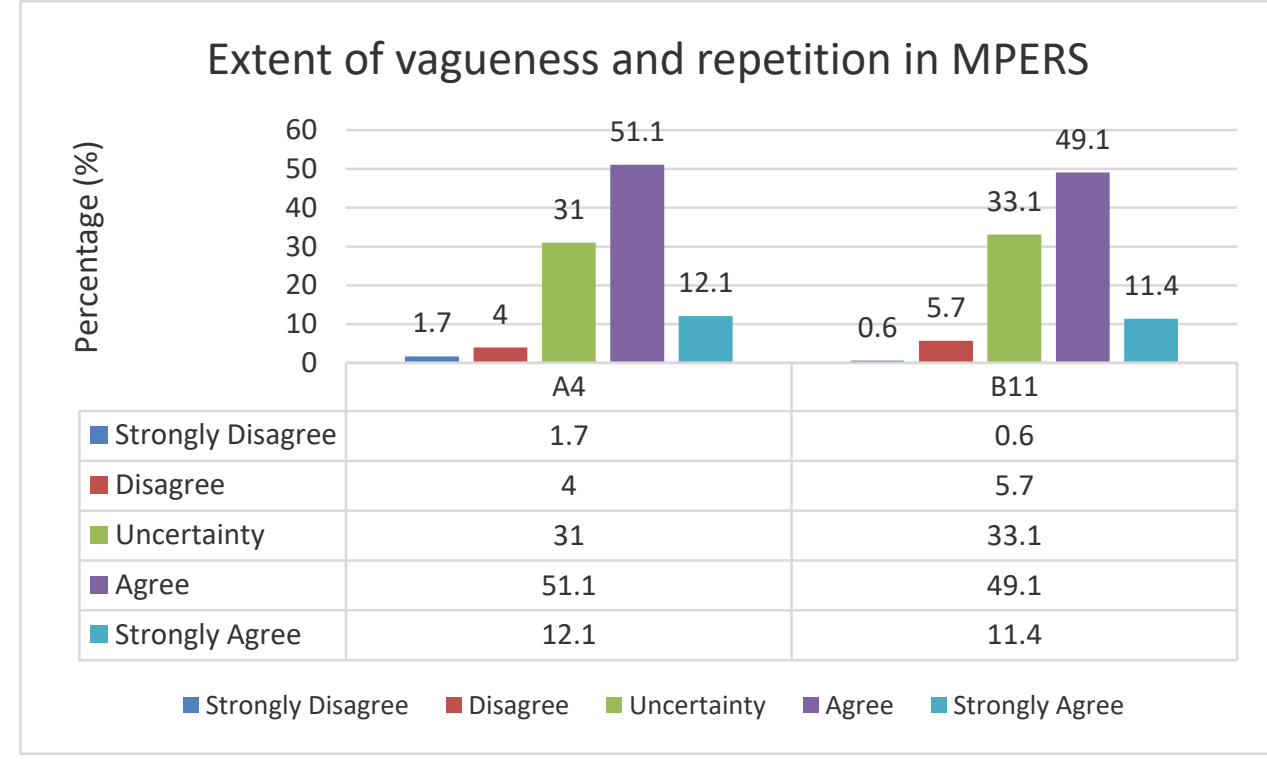

\begin{tabular}{|l|l|}
\hline \multicolumn{2}{|c|}{ Extent of vagueness and repetition in MPERS } \\
\hline A & MPERS contain expressions that are lacking clarity. \\
\hline B & Individual paragraphs within MPERS are repetitive. \\
\hline
\end{tabular}

\section{Extent of understandability}

In the questionnaire, there were quite few numbers of questions highlighting the issue of understandability. For instance, Question 3 and Question 5, 48\% and 40\% of the respondents claimed that MPERS in general is not easy to understand or the vocabulary used is not understandable. In addition to that, the paragraph coding of MPERS seems confusing to the readers ( Question 12) as 44.8\% agreed with the statements and about 49.7\% highlighted that the structure of MPERS are difficult to follow (Question 13). Some respondents represented by $46.9 \%$ agreed to have difficulties in terms of the alternative treatment given in MPERS (Question 16). Furthermore, 53.7\% of the accounting practitioners said that they difficult to understand the terms used in MPERS (Question 24).

These comments suggested that the structure of MPERS need to be revised and the language used should be in general understanding of the readers that used the standard. The inherent problem that may arise due to the understandability issue is that the technical language can become a barrier for the practitioners to interpret the standard (Young, 2003). Besides that Young (2003) also mentioned that only an expert could succeed in 'untangling the complicated phrasing and in using the highly specialized language of accounting'. For this reason, it become a cost for small business to overcome the issues. 


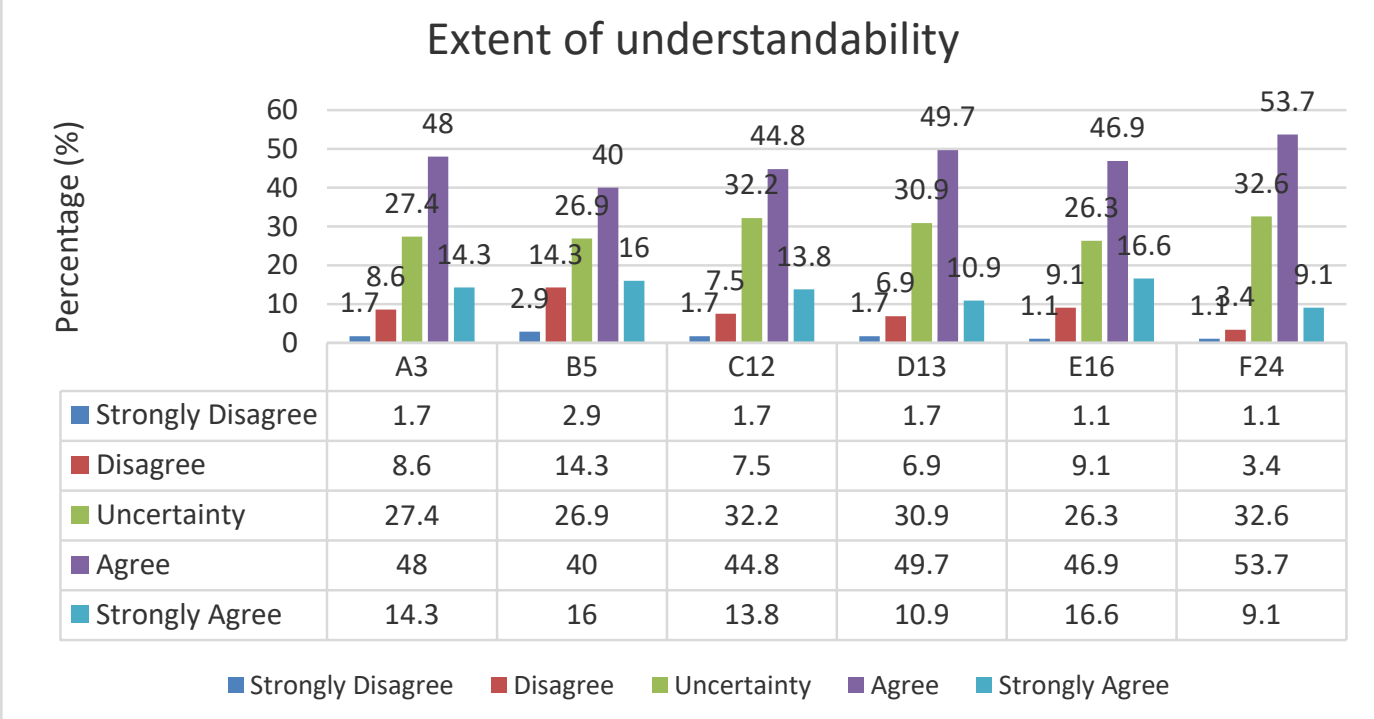

\begin{tabular}{|l|l|}
\hline \multicolumn{2}{|l|}{ Extent of understandability } \\
\hline A & MPERS in general are not easy to understand. \\
\hline B & The vocabulary used in MPERS is difficult to understand. \\
\hline C & The paragraph coding in MPERS is confusing. \\
\hline D & MPERS are structured in a way that is difficult to follow. \\
\hline E & The alternative treatments given in MPERS are not easy to understand. \\
\hline F & It is difficult to capture the meaning of some terms in MPERS. \\
\hline
\end{tabular}

\section{Extent of guidance provided}

There were five questions (Questions 18,19,26,27 and 28) stated on the survey regards to the sufficient guidance in the interpretations and application of MPERS for SMEs. Based on the result, $55.7 \%$ of the accounting practitioners claimed that MPERS do not provide adequate guidance to assist accountants in interpreting and applying the standard (Question 18). Similarly, 52\% of the respondents pointed out that MPERS do no provide guidance to address the social and economics characteristic of SMEs (Question 19). This is normally related to the translation of foreign currency and measurement of fair value accounting and the effect on tax in the context of SMEs in Malaysia.

In addition, the respondents were asked how often they need to consult with other resources such as employers, superior staff when applying MPERS (Question 26). Almost 59.4\% of them agreed that they have to consult with other resources when applying the MPERS. Moreover, within the survey, it is also included the professional judgement by the respondents regards to the guidance of MPERS. Question 27 and Question 28,50.3\% and $53.7 \%$ respectively of the respondents agreed whether the professional accountants have always reached the same judgement or any disagreement regards to the implementation of MPERS.

These answers reflected the extend of guidance provided within the MPERS are lacking and 
therefore the amount of efforts is needed to assist the professional accountant to exercise their professional judgement while conducting their duties. Messier et al. (2008) mentioned in order the accounting practitioners to make professional judgement when choosing appropriate accounting policies, making suitable accounting estimates and determining what information should be disclosed in the financial statement, the comprehensive guidance are highly needed.

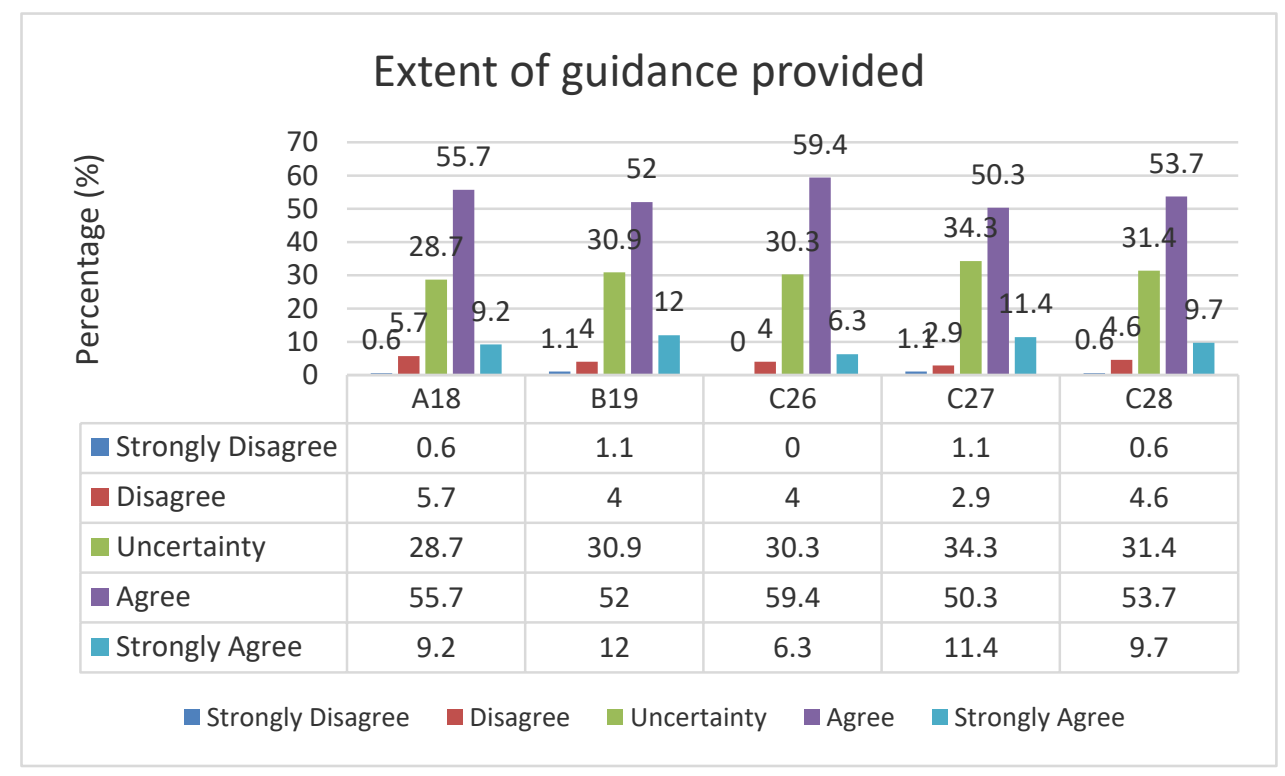

\begin{tabular}{|l|l|}
\hline \multicolumn{2}{|l|}{ Extent of guidance provided } \\
\hline A & $\begin{array}{l}\text { MPERS do not provide adequate guidance to assist accountants in interpreting and } \\
\text { applying this standard. }\end{array}$ \\
\hline B & $\begin{array}{l}\text { MPERS do not provide adequate guidance to address the social and economic } \\
\text { characteristics of SMEs in Malaysia. }\end{array}$ \\
\hline C & $\begin{array}{l}\text { How often do you need to consult with other resources, such as manuals provided by } \\
\text { employers, consultation with senior staffs, etc., when applying MPERS? }\end{array}$ \\
\hline D & $\begin{array}{l}\text { Do you think different professional accountants will always reach the same judgement on } \\
\text { a specific scenario under the guidance of MPERS? }\end{array}$ \\
\hline E & $\begin{array}{l}\text { Have you ever been in disagreement with your colleagues when deciding which } \\
\text { alternative treatment given by MPERS is the most appropriate to employ in a particular } \\
\text { scenario? }\end{array}$ \\
\hline
\end{tabular}

\section{Other issues in interpreting and applying MPERS}

There were other issues faced by the professional accountant when interpreting and applying the MPERS. Seven questions were raised (Question 2,6,8,10,17,20 and 22) based on their experiences while implementing the MPERS.

The result shows that $46.6 \%$ of the respondents agreed that they need extensive 
cross-referencing to IFRS is required while interpreting and applying the MPERS (Question2). Furthermore, 48\% of the respondents indicated that the nature, volume and complexity of disclosure required by MPERS is excessive (Question 6). This is consistent with Handley et al. (2018) on the issues of loss of confidential information to competitors as disclosure of too much information to competitors could threaten the sustainability of SMEs.

Regards to the issues of fair value accounting, about 53.7\% of the respondents agreed that the use is excessive (Question 8). This is because the concern mostly related to the technical aspect of fair value itself that tend to make the MPERS become complicated in nature. The complexity of MPERS sought in Question 17 which around $46.3 \%$ of the respondents agreed on that.

In different elements of reporting, it is highlighted from the Question 20 that different tier of reporting is needed for small business entities. $57.7 \%$ of the respondents agreed on different tier of reporting perspective as among the advantages on different tier is that it is independently developed standard that the specific issues and circumstances of the local context types of small entities in Malaysia can be incorporated into the standard.Finally, regards the issue of some transactions, events or conditions that SMEs engage in that are not covered in MPERS (Question 22). 55.4\% of the respondents claimed that some transactions are not covered in MPERS for instance for a property developer they may opt to use MFRS because MPERS requires all borrowing costs to be expenses in the profit and loss. The capitalization of borrowing costs, subject to fulfillment of certain criteria, is allowed under MFRS framework. In addition, MFRS may be the preferred option for a private entity that has a huge amount of intangible assets or goodwill because MPERS requires all intangible assets whose useful life cannot be established reliably to be amortised over 10 years. MFRS have a different accounting treatment in this area where goodwill is not amortised but tested for impairment annually.

These comments suggest it is important for the business to consider their long term business plan when making decision especially if they plan to get listed in the stock exchange. Practically, the companies to adopt policies which is consistent through out their operations. Therefore, the business needs to carefully make a choice which financial reporting framework is most beneficial for them. 


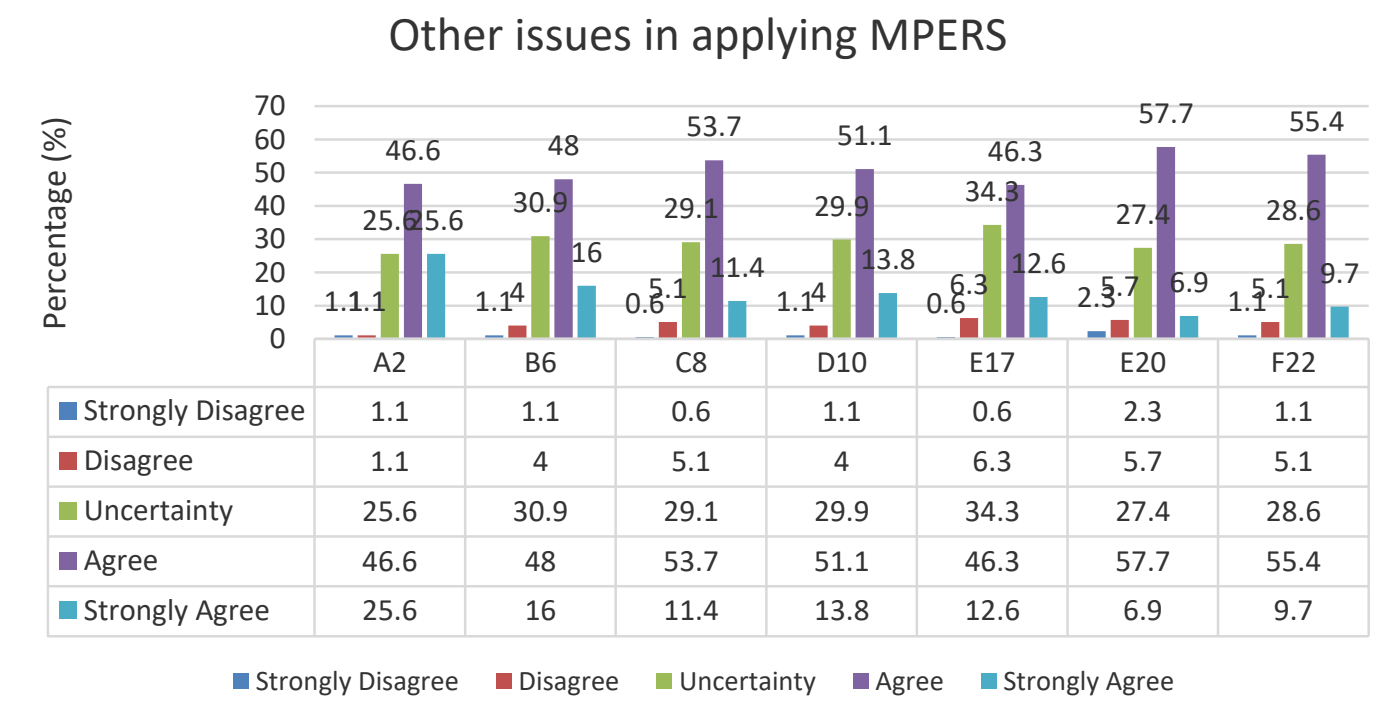

\begin{tabular}{|l|l|}
\hline \multicolumn{2}{|l|}{ Other issues in applying MPERS } \\
\hline A & Extensive cross-referencing to IFRS is required while interpreting and applying MPERS. \\
\hline B & The nature, volume and complexity of disclosure required by MPERS is excessive. \\
\hline C & The use of fair value accounting (FVA) is excessive in MPERS. \\
\hline D & The need to exercise professional judgement is excessive in MPERS. \\
\hline E & MPERS is too complex for SMEs in Malaysia. \\
\hline F & $\begin{array}{l}\text { There is a need to create an additional tier of differential reporting framework in Malaysia } \\
\text { for really small (micro) entities. }\end{array}$ \\
\hline G & $\begin{array}{l}\text { There are transactions, events or conditions that SMEs engage in that are not covered in } \\
\text { MPERS. }\end{array}$ \\
\hline
\end{tabular}

\section{Conclusion and Recommendations}

The main objective of this paper was to 1) examine the perceptions of accounting practitioners on MPERS implementation and 2) identify the problems encountered in applying MPERS in SMEs. To provide the pioneer evidence of the problems that the accounting practitioners encountered when applying and interpreting the MPERS, the study have conducted a survey on accounting practitioners in Malaysia. Therefore, based on the results there has also been a notable number of problem regards to the MPERS implementation such as lack of consistency, the extent of understandability, the extent of guidance, the extent of vagueness and other issues related to the professional judgement using the MPERS.

The views and comments provided by the accounting practitioners imply that MPERS for SMEs do not adequate guidance in assisting them to exercise their professional judgements. Almost half of the respondents by percentage basis claimed that they need to refer to other sources or further inquiries need to be made from the senior staff when applying the MPERS. 
Overall, the result indicates problems among the practitioners in which greater effort need to be taken especially by the regulator or standard setter in reducing the conflicting judgement made by the professional accountant when interpreting the standard.

Certain limitations of this study need to be highlighted. The discussion on the implementation issues arises for SMEs was based on the survey questionnaire which limit the scope of the study. In depth analysis through interview could be undertaken for future research to reveal in what the actual implementation difficulties and issues encountered for MPERS. In addition, future research could be explored on the determinants of MPERS adoption as various industries have various need to use MPERS as their reporting standard.

\section{Acknowledgement}

This research is benefited from the funding from Malaysia Ministry of Education for the FRGS Funding with Code: FRGS/1/2018/SS01/USIM/02/3 and UniversitiSains Islam Malaysia (USIM) with Code: USIM/FRGS/FEM/055002/51518 (Benchmarking Malaysian Private Entity Reporting Standard in Malaysia in Achieving High Income Nation).

\section{References}

Aziz, S. A., Bakar, F. A., \& Latif, R. A. (2019). The readiness and Challenges of the Malaysian Private Entities Reporting Standard (MPERS).International Journal of Innovation , Creativity and Change, 5(2), 1621-1634.

Buchanan, R. F. (2003). International accounting harmonization: Developing a single world standard. Business Horizon (May-June), 61-70.

https://doi.org/10.1016/S0007-6813(03)00030-2

Coppens, C., Van-Wymeersch, K., Van-Hecke, A., Engels, L., De Lembre, E., De Beelde, I., Verhoeye, J., \& Van De Velde, G. (2007). An Investigation into the Attitude of Belgian SMEs Towards the Implementation of IAS/ IFRS. Annual Conference of the European Accounting Association, Lisbo.

Eva, H. (2019). The current problems of harmonization of accounting for small and medium-sized enterprises. Economic Research-Ekonomskalstraživanja, 32(1), 604-621. https://doi.org/10.1080/1331677X.2018.1561317

Fearnly, S., \& Hines, T. (2007). How IFRS has destabilised financial reporting for UK Non-listed entities. Journal of Financial Regulation and Compliance, 15(4), 394-408. https://doi.org/10.1108/13581980710835254

Haller, A. (2002). Financial accounting developments in the European Union: Past events and future prospects. European Accounting Review, 11(1), 153-190.

https://doi.org/10.1080/09638180220124770

Handley, K., Wright, S., \& Evans, E. (2018). SME Reporting in Australia: Where to Now for Decision-usefulness?.Australian Accounting Review, 28(2), 251-265.

https://doi.org/10.1111/auar.12179 
Harvey, D., \& Walton, P. (1996). Differential Reporting - an analysis. London: The Foundation for Manufacturing and Industry.

Herman, N. (2010). IFRS for SMEs: Not for private American companies. The CPA Journal, $80(12), 11-12$

Holmes, S., Kent, P., \& Downey, G. (1991). The Australian Differential Reporting Debate: A Survey of Practioners. Accounting \& Business Research, 21(82), 125-132. https://doi.org/10.1080/00014788.1991.9729825

Isidro, H., Nanda, D., \& Wysocki, P. D. (2016). Financial Reporting Differences Around the World: What Matters?. https://doi.org/10.2139/ssrn.2788741

Jamil, N. N., Ramli, N. M., Marzuki, A., \& Ahmad, N. N. (2020). Malaysian Private Entity Reporting Standard (MPERS) For Small Medium Enterprises in Malaysia: Value Adding or Additional Pain?. Perdana International Journal of Academic Research, 7(1), 16-28.

Lalin, H., \& Sabir, R. I. (2010, May). Research on usage and usefulness perception of financial accounting practices in less developing countries: A case of Cambodia. Proceedings of the 7th International Conference on Innovation \& Management, Cambodia.

Maingot, M., \& Zeghal, D. (2006). Financial reporting of small business entities in Canada. Journal of Small Business Management, 44(4), 513-530.

https://doi.org/10.1111/j.1540-627X.2006.00191.X

McMahon, R. G. P., \& Holmes, S. (1991). Small business financial management practices in North America: A literature review. Journal of Small Business Management, 29(2), 19-29.

McMahon, R. G. P. (1999). Recent SME research: A critical review. Small Enterprise Research: The Journal of SEAANZ, 7(1), 68-75. https://doi.org/10.5172/ser.7.1.68

Messier, W. F., Emby, C. E. N., Glover, S. M., \& Prawitt, D. F. (2008). Auditing \& Assurance Services: A Systematic Approach (3rd Ed.). McGraw-Hill Ryerson Limited. Toronto: ON.

Nunnally, J. C. (1978). Psychometric Theory. New York. NY McGraw-Hill.

Rahman, A. A., \& Hamdan, M. D. (2019). An Investigation of the Level of Compliance with Financial Reporting Standards (FRS 101) by Malaysian SMEs. Journal of Economic Info, 6(1), 26-33. https://doi.org/10.31580/jei.v6i1.496

Olson, O., Blomskvisk, M., Dergard, J., \& Jonsson, C. (2004, July). Accounting and entrepreneurship: A review and discussion of the scientific literature. Paper Presented at the 4th Asia-Pacific Interdisciplinary Research in Accounting Conference, Singapore

Pais, C. A. F., \& Bonito, A. L. M. (2018). The macroeconomic determinants of the adoption of IFRS for SMEs. Revista de Contabilidad-Spanish Accounting Review, 21(2), 116-127. https://doi.org/10.1016/j.rcsar.2018.03.001

Vanauken, H. E., Ascigil, S., \& Carraher, S. (2017). Turkish SMEs' use of financial statements for decision making. The Journal of Entrepreneurial Finance (JEF), 19(1). 
Walton, P. (1992). Differential reporting and the European Community - a suitable case for treatment. European Business Journal, 13-49.

Walton, P., Haller, A., \& Raffournier, B. (2003). International Accounting (2nd ed.). London: Thomson.

Wichman, H. (1983). Accounting and marketing - Key small business problems. Am. J. Small Bus, 7(4), 19-26. https://doi.org/10.1177/104225878300700404

Young, J. J. (2003). Constructing, Persuading and Silencing: The Rhetoric of Accounting Standards. Accounting, and Society, 28(6), 621-38.

https://doi.org/10.1016/S0361-3682(02)00016-8

Zebda, A. (1991). The problem of ambiguity and vagueness in accounting. Behaviour Research in Accounting, 3, 117-145.

\section{Appendix}

\section{Appendix 1}

Table 4. A summary of the 28 statements to explore on the perceptions of accounting practitioners in implementation of MPERS for SMEs in Malaysia

\begin{tabular}{|c|c|c|}
\hline Statements & Mean & $\begin{array}{l}\text { Standard } \\
\text { Deviation }\end{array}$ \\
\hline $\begin{array}{l}\text { 1. The costs of complying with the MPERS are far greater than the corresponding } \\
\text { benefits. }\end{array}$ & 3.972 & 0.7516 \\
\hline $\begin{array}{l}\text { 2. Extensive cross-referencing to IFRS is required while interpreting and applying } \\
\text { MPERS. }\end{array}$ & 3.943 & 0.8122 \\
\hline 3. MPERS in general are not easy to understand. & 3.642 & 0.8895 \\
\hline 4. MPERS contain expressions that are lacking clarity. & 3.670 & 0.8032 \\
\hline 5. The vocabulary used in MPERS is difficult to understand. & 3.517 & 1.0140 \\
\hline 6. The nature, volume and complexity of disclosure required by MPERS is excessive. & 3.739 & 0.8141 \\
\hline $\begin{array}{l}\text { 7. The information required to apply MPERS is not available or available with only } \\
\text { undue cost or effort. }\end{array}$ & 3.693 & 0.8466 \\
\hline 8. The use of fair value accounting (FVA) is excessive in MPERS. & 3.705 & 0.7583 \\
\hline $\begin{array}{l}\text { 9. The use of FVA in MPERS imposes significant annual costs on preparers and is not } \\
\text { justified on cost/benefit grounds. }\end{array}$ & 3.676 & 0.7427 \\
\hline 10. The need to exercise professional judgement is excessive in MPERS. & 3.722 & 0.7905 \\
\hline 11. Individual paragraphs within MPERS are repetitive. & 3.653 & 0.7778 \\
\hline 12. The paragraph coding in MPERS is confusing. & 3.614 & 0.8742 \\
\hline 13. MPERS are structured in a way that is difficult to follow. & 3.614 & 0.8340 \\
\hline 14. Recognition criteria applied are not applied consistently across the MPERS. & 3.665 & 0.8855 \\
\hline 15. Measurement criteria applied are not applied consistently across the MPERS. & 3.540 & 0.8807 \\
\hline 16. The alternative treatments given in MPERS are not easy to understand. & 3.687 & 0.8938 \\
\hline
\end{tabular}




\begin{tabular}{|l|l|l|}
\hline 17. MPERS is too complex for SMEs in Malaysia. & 3.642 & 0.8016 \\
\hline $\begin{array}{l}\text { 18. MPERS do not provide adequate guidance to assist accountants in interpreting } \\
\text { and applying this standard. }\end{array}$ & 3.670 & 0.7441 \\
\hline $\begin{array}{l}\text { 19. MPERS do not provide adequate guidance to address the social and economic } \\
\text { characteristics of SMEs in Malaysia. }\end{array}$ & 3.699 & 0.7747 \\
\hline $\begin{array}{l}\text { 20. There is a need to create an additional tier of differential reporting framework in } \\
\text { Malaysia for really small (micro) entities. }\end{array}$ & 3.614 & 0.7918 \\
\hline $\begin{array}{l}\text { 21. Additional exemptions need to be given in MPERS to make it cost effective for } \\
\text { SMEs in Malaysia. }\end{array}$ & 3.761 & 0.7406 \\
\hline $\begin{array}{l}\text { 22. There are transactions, events or conditions that SMEs engage in that are not } \\
\text { covered in MPERS. }\end{array}$ & 3.676 & 0.7655 \\
\hline 23. Certain terms are not defined in the same way across the MPERS. & 3.699 & 0.7523 \\
\hline 24. It is difficult to capture the meaning of some terms in MPERS. & 3.665 & 0.7376 \\
\hline 25. Some terms in MPERS are used inconsistently. & 3.716 & 0.7993 \\
\hline $\begin{array}{l}\text { 26. How often do you need to consult with other resources, such as manuals provided } \\
\text { by employers, consultation with senior staffs, etc., when applying MPERS. }\end{array}$ & 3.682 & 0.6511 \\
\hline $\begin{array}{l}\text { 27. Do you think different professional accountants will always reach the same } \\
\text { judgement on a specific scenario under the guidance of MPERS? }\end{array}$ & 3.682 & 0.7566 \\
\hline
\end{tabular}

\section{Copyright Disclaimer}

Copyright for this article is retained by the author(s), with first publication rights granted to the journal.

This is an open-access article distributed under the terms and conditions of the Creative Commons Attribution license (http://creativecommons.org/licenses/by/4.0/). 